\title{
A REPRESENTAÇ̃̃o DE MARINA NO ROMANCE ANGÚSTIA, DE GRACILIANO RAMOS
}

\author{
MARINA'S REPRESENTATION IN THE NOVEL ANGÚSTIA, FROM GRACLIIANO RAMOS
}

\begin{abstract}
RESUMO
É objetivo nosso estudar a representação de Marina, no romance Angústia, de Graciliano Ramos, a fim de averiguar como a personagem figura no plano da narrativa, tendo em vista que sua imagem é construída a partir da ótica de um sujeito em profundo estado de perturbação, além das forças de conflitos vigentes, materializadas pelo sistema patriarcal. Como procedimento metodológico, optou-se por um estudo bibliográfico, com o suporte de material já publicados pertinentes a esta pesquisa. As considerações aqui tecidas são embasadas por Alfredo Bosi (1979), Afrânio Coutinho (1997), Antonio Candido (2006 \& 1999), Fernando Cerisara Gil (1997), Losandro Antônio Tedeschi (2014), Carlos Nelson Coutinho (1978), Marcos Hidemi de Lima (2006), entre outros. Visto que a construção da referida personagem feminina se dá pela visão de um sujeito patriarcal em plena degradação da experiência humana, foi possível perceber a situação de imobilidade advinda do sistema e da visão que oprimem a mulher.
\end{abstract}

Palavras-chave: Graciliano Ramos. Angústia. Representação feminina.

\begin{abstract}
We aim to study Marina's representation in the novel Angústia, by Graciliano Ramos, in order to ascertain how the feminine character figures in the narrative plane, taking into account that her image is constructed through the optics of a subject in a deep state of disturbance, beyond the conflicting forces at that time, materialized by the patriarchal system. As methodologic procedure, we develop a bibliographic study, with the support of already published material that is pertinent to this research. Our discussion is here supported by Afrânio Coutinho (1997), Antonio Candido (2006 \& 1999), Fernando Cerisara Gil (1997), Losandro Antônio Tedeschi (2014), Carlos Nelson Coutinho (1978), Marcos Hidemi de Lima (2006), among others. Since the construction of the female character is presented through the vision of a patriarchal subject full degraded in terms of human experience, it was possible to realize the immobility coming from an oppressive system in respect to women.
\end{abstract}

Keywords: Graciliano Ramos. Angústia. Feminine representation.

Everton Vinícius Araujo Silva

Universidade Estadual de Alagoas. E-mail: ev.araujo1994@hotmail.com

Helenice Fragoso dos Santos

Professora assistente Letras- Universidade Estadual de Alagoas. E-mail: nicefragoso@hotmail.com 


\section{Considerações iniciais}

É bem verdade que a segunda fase do movimento modernista é considerado pela crítica especializada como o momento de amadurecimento do movimento iniciado em 1922, na Semana de Arte Moderna, e entre 1930 e 1945 produziu obras cujo principal enfoque se dá na denúncia social do que acontecia no Nordeste, região até então fadada ao descaso. Além de romances puramente regionais, encontra-se a prosa psicológica, subjetiva e universal do escritor alagoano Graciliano Ramos.

Daí que Sarmento Lima (2019) titula o escritor acima referenciado de voz isolada (informação verbal)' , visto que a denúncia social não lhe tema basilar. Em seus romances, o escritor alagoano abordou os problemas do homem dentro de si mesmo, como bem pontuou Wilson Martins (1978).

Das vertentes da prosa modernista da segunda fase, Afrânio Coutinho classifica Graciliano como pertence à "corrente psicológica, subjetiva, introspectiva e costumista". (COUTINHO, 1997: 276), visto o enfoque principal do romancista à sua obra é justamente os problemas da alma. Ainda assim, é de conhecimento que Graciliano recusou a classificação como modernista, todavia, é possível perceber elementos originários da semana de 1922 em sua escrita, como salienta os/as estudiosos, como a recusa à linguagem "bacharelesca", segundo Lafetá (2001: 21). A introspecção e a linguagem do caboclo, segundo disse o romancista alagoano em entrevista a Homero Senna, podem ser encontradas ao longo de sua produção.

E é neste quadro que se insere a narrativa memorialística de Luís da Silva, Angústia, um funcionário público com aptidões para a escrita e que trabalha na repartição de um jornal. Encanta-se por sua recente vizinha, Marina, e a pede em casamento. Esta é atraída por Julião Tavares, oponente do narrador, que concentra em si aspectos almejados pelo protagonista, como riqueza e mulheres. Sucumbido pela inveja, Luís resolve assassinar seu rival enforcando-o.

Tendo em visto que a figuração da personagem feminina Marina é construída através da perspectiva de um sujeito profundamente marcado pela opressão, legamos estudo neste artigo à representação da referida personagem, visto que "[...] a percepção falha e incompleta" (CANDIDO, 2006: 119) de Luís da Silva força o leitor a repensar a figuração da personagem feminina na obra.

Para tal, realizou-se uma pesquisa de essencialmente bibliográfico sob a justificativa de que tal estratégia proporcionará o alcançar dos resultados em materiais já publicados, tais como livros, teses e dissertações que abordam a temática da produção literária do Mestre Graça bem como o tema referente à obra aqui em estudo.

Inicialmente, tecemos algumas considerações sobre o romance Angústia, elencando algumas características que possam contribuir para a importância deste na produção romanesca de Graciliano e no quadro geral da literatura

1 Esta informação foi exposta pelo Prof. Dr. Roberto Sarmento Lima, professor da Universidade Federal de Alagoas, em palestra intitulada "Graciliano Ramos - Uma voz isolada no romance de 1930", na $2^{\text {a }}$ Festa Literária de Palmeira dos Îndios, no dia 25 de outubro de 2019. 
brasileira. Posteriormente, adentramos o estudo sobre a representação de Marina, empreendendo um esforço a fim de averiguar como esta personagem se configura no plano da narrativa.

\section{Considerações sobre angústia}

Angústia é o terceiro romance de Graciliano Ramos, publicado em 1936. Narrado em primeira pessoa, o livro conta a história de Luís da Silva, funcionário público com tendência a gostos literários, cuja mísera vida é abastada de uma experiência degradante de vivência humana. Segundo Bosi (1979: 453): "A existência de Luís da Silva arrasta-se na recusa e na análise impotente da miséria moral de seu mundo e, não tendo outra saída, resolve-se pelo crime e pela autodestruição.”

Decorrido hiato de um ano, o protagonista resolve contar os acontecimentos de sua vida no período de tempo transcorrido. Romance memorialístico, os fatos estão à mercê daquele que conta, deste modo, a perspectiva da narrativa, que delimita o campo de visão do mundo narrado, sofre as interferências da subjetividade de Luís da Silva, que imprime suas impressões acerca do que observa: paisagens, personagens, objetos, entre outros.

Assim, a preocupação de Graciliano Ramos em analisar a subjetiva do indivíduo, a fim de colocar a personalidade humana em face de si mesma, adentra a mente do funcionário público, cujos pensamentos mais íntimos são postos ao olho do leitor. Tamanha introspecção é possível pelo uso de determinadas técnicas narrativas as quais Graciliano conhecia bem, em decorrência de seu vasto repertório de leitura - Honoré de Balzac, Émile Zola, dentre outros -, como pode ser constatado em sua biografia, O velho Graça (2012).

Outrossim, Angústia apresenta mais dois traços de caráter ímpar na produção graciliânica: ao contrário de Caetés (1933) e S. Bernardo (1934), inexiste uma divisão em capítulos, assim como também o título do romance é um substantivo abstrato. Como advoga Antonio Candido (1999: 79):

A complexidade chega ao máximo em Angústia (1936), que ao contrário dos outros é longo e desenvolve com detalhe a análise interior, contando, também na primeira pessoa, o drama de um medíocre desajustado, que compensa a fraqueza pelo crime, configurado lentamente nas suas elucubrações, ao longo de uma narrativa tortuosa e patética.

Salientando o termo complexidade, citado acima pelo crítico, a utilização do tempo no terceiro romance do escritor de Vidas Secas é algo a ser considerado: de modo não linear, a temporalização da narrativa memorialística de Luís da Silva não se faz cronológica, mas estilhaçada. 
A narrativa não flui, como nos romances anteriores. Constrói-se aos poucos, em fragmentos, num ritmo de vaivém entre realidade presente, descrita com saliência naturalista, a constante evocação do passado, a fuga para o devaneio e a deformação expressionista. (CANDIDO, 2006: 113)

O método de tempo fragmentado, estilhaçado, alimentado pela imaginação enraivecida do apaixonado, segundo pontua Silviano Santiago (2013) é adverso quanto ao caráter cronológico da vida humana, justamente por representar a realidade subjetiva e caótica do protagonista. Nas palavras de Cerisara Gil (1997: 96), isso gera:

[...] implicações profundas no andamento da prosa do romance ao impedir que esta tome algum fluxo direcional, fazendo, ao mesmo tempo, com que se constitua de marchas e contramarchas, de idas e vindas, como se a sua natureza prismática tivesse o efeito único de gerar imobilidade em todas as direções e sentidos que o protagonista pudesse querer imprimir à sua vida.

De maneira a ilustrar a fragmentação temporal decorrente na narrativa, observe-se o enxerto abaixo:

Rua do Comércio. Lá estão os grupos que me desgostam. Conto as pessoas conhecidas: quase sempre até os Martírios encontro umas vinte. [...] Afasto-me outra vez da realidade, mas agora não vejo os navios, a recordação da cidade grande desapareceu completamente. O bonde roda para oeste, dirige-se ao interior. [...] E nem percebo os casebres miseráveis que trepam o morro, à direita, os palacetes que têm os pés na lama, junto ao mangue, à esquerda. Quanto mais me aproximo de Bebedouro mais remoço. [...] Volto a ser criança, revejo a figura de meu avô, Trajano Pereira de Aquino Cavalcantee Silva, quealcancei velhíssimo. Os negócios na fazenda andavam mal. E meu pai, reduzido a Camilo Pereira da Silva, ficava dias inteiros manzanzando numa rede armada nos esteios do copiar, cortando palha de milho para cigarros, lendo o Carlos Magno, sonhando com a vitória do partido que padre Inácio chefiava. (RAMOS, 1986: 8)

Somando-se ao que foi exposto, tem-se também a prisão de Graciliano Ramos no dia em que entregou os manuscritos de Angústia, impossibilitando que o escritor pudesse eliminar páginas e até mesmo mundos inteiros, como afirma Carpeaux (1978), referindo-se aos crivos que Ramos utilizava ao terminar seus romances, pois o literato tinha o hábito de retirar o que não considerasse necessário. Não podendo eliminar a "excessiva gordura", expressão cunhada pelo autor para se referir àquilo que devia ser removido de seu romance, causou-lhe irritação: "Não se conferiu a 
cópia com o original. Imagine. E a revisão preencheu as lacunas metendo horrores na história. Só muito mais tarde os vi." (RAMOS apud MORAES, 2012: 113)

Graciliano não esperava que sua narrativa sobre Luís fosse tão bem recebida pela crítica da época, mesmo que alguns críticos apontassem que $S$. Bernardo fosse seu maior romance: "Dos livros de Graciliano Ramos, Angústia é provavelmente o mais lido e citado, pois a maioria da crítica e dos leitores o considera a sua obraprima." (CANDIDO, 2006: 47)

Angústia, mais que substantivo nomeador do romance, torna-se adjetivo do mesmo ao caracterizar a sufocante atmosfera norteadora da história. Moraes, ao contextualizar o mundo no período de produção do romance de Graciliano Ramos de 1936 afirma: "O clima sufocante de Angústia perderia substância sem a analogia com a assustadora ascensão do fascismo e suas nefastas ressonâncias entre nós durante o Estado Novo." (MORAES, 2012: 17). Tal clima nos é passado pelo protagonista, já que o anti-herói, como afirma Candido (2006: 50): “[...] assimila o mundo ao seu mundo interior."

Quanto ao personagem-narrador, observa-se a perpetuação de uma vida marcada pela opressão: "[...] ele é por excelência o selvagem, o bicho, escondido na pele dum burguês medíocre." (CANDIDO, 2006: 114). Concebido em uma sociedade rural e patriarcal, remete-se constantemente ao seu passado na fazenda do avô, decadente fazendeiro senhor de escravizados e de quem nada herdou, pois a propriedade e os demais bens da família encontravam-se em estado de precariedade ou para liquidar dívidas. De acordo com Candido, Luís da Silva é tomado por:

[...] uma fúria evidente contra a sua vida e a sua pessoa, pelas quais não tem a menor estima [...] Luís da Silva se anula pela autopunição e só consegue equilibrar-se assassinando o rival, equilíbrio precário que o deixa arrasado, mas de qualquer modo é a única maneira de afirmar-se. (CANDIDO, 2006: 48-49)

Certo dia conhece Marina, da qual se enamora e deseja se casar, e a esta entrega sua pouca renda para um possível enxoval. Aparece então o antípoda Julião Tavares, rico, bacharel - possível representante da nova ordem social burguesa -, por quem Marina se deixa seduzir. Negado outra vez, assim como lhe fora tirada a herança do avô, o funcionário público não consegue realizar seu desejo de possuí-la e ter uma vida socialmente estável'. Sentindo-se outra vez humilhado, nutre ao decorrer da narrativa uma ânsia de assassinato, a qual realiza estrangulando o rival, e após um surto, abalado pelo que fez, escreve sobre os fatos que o afligiram.

Assim é que, a subjetividade impressa ao romance pela perspectiva em primeira pessoa, que transmite ao leitor as impressões daquele que narra, são acessíveis pelo olhar subversivo e modificado de Luís da realidade, assim: "[...] a realidade se produz como objeto da consciência do personagem [...]" (GIL, 1997: 95), já que Angústia, ainda nas palavras do estudioso, “[...] elabora-se, em boa parte, como dissolução da 
realidade objetiva em estados mentais subjetivos do personagem Luís da Silva." (GIL, 1997: 95)

Tal visão, ainda segundo Gil (1997), decorre do corte espaço-temporal da vivência do narrador-personagem, já que ele existe em um contexto de conflito entre tempos históricos diferentes; uma sociedade rural e patriarcal já em decadência Luís da Silva evoca constantemente lembranças da época de infância na fazenda do avô - e a sociedade industrial, urbana e burguesa.

[...] Angústia de modo particular, e no romance da urbanização de modo geral, é o conflito de dois tempos históricos distintos que correspondem a espaços e valores sociais e culturais também diversos e que, até certo ponto formalizam-se no nível estético como irreconciliáveis para a vida do nosso protagonista. (GIL, 1997: 92, grifo do autor)

O monólogo interior, o tempo estilhaçado, o uso do psiquismo, o ambiente que remete ao substantivo abstrato nomeador e norteador do romance, a subjetivação da realidade, a interiorização do mundo e todo o caráter experimental que se materializa no romance, demonstra-nos a riqueza da escrita de Graciliano Ramos, de modo a perceber em Angústia um romance que representa bem mais do que apresenta, e tais elementos fundem-se simbioticamente para a composição do livro vanguardista da geração moderna de 1930 .

\section{Estudo sobre a representação de Marina}

No panorama acerca da situação da mulher na história, iniciando as considerações a partir de Roma antiga, Tedeschi (2012) afirma que tanto o uso da linguagem bem como as discussões que havia nas praças fora negado à mulher. Tal quadro permanecerá estático nos séculos à frente. No início da segunda metade do século passado é que diversos movimentos e discussões puseram no cerne dos debates grupos marginalizados, tais como índios, negros e mulheres, a fim de trazer novas perspectivas, vozes e discursos, indo em contrapartida à história tradicional.

No decorrer da história há uma relação entre gênero e poder que precisa ser estudada, revelada, reescrita, pois a história tradicional antropocêntrica e universalizante criou o mito do sexo frágil, da impotência feminina e da sua dependência existencial do masculino. (TEDESCHI, 2014: 9)

Em conformidade com estudioso, tradicionalmente construído sob a ótica masculina, o discurso patriarcal unificou a figura da mulher às categorias de 
reprodução e maternidade, com alegações fundadas no que ele pontuou como "natureza feminina".

\begin{abstract}
Abordar a construção dessas representações é revelar o imaginário masculino presente, impregnado, refletido na cultura. Tradicionalmente se empregam argumentos extraídos da natureza, da religião, do político para legitimar a subordinação feminina. (TEDESCHI, 2014: 15)
\end{abstract}

Abordar, destarte, a construção de tais representações em obras na qual a mulher se presentifica e especialmente naquelas em que se torna objeto construído a partir da perspectiva de um sujeito alienado, é o objetivo deste artigo. Ao estudar a personagem Marina, espera-se poder, ainda nas palavras de Tedeschi (2014), “[...] revelar o imaginário masculino presente”, apresentando como determinada personagem é manifestada na narrativa, considerando que esta é representada pela ótica de um indivíduo de raízes patriarcais profundamente marcado pela humilhação.

Para tal, cabe ressaltar que Angústia é uma narrativa memorialística, cuja visão preponderante é de seu protagonista, Luís da Silva. Todas as demais personagens da obra estão sujeitas à sua percepção e consequente projeção, já que só temos acesso àquilo o que ele vê e, portanto, percebe.

Conforme ressalta Tedeschi (2012), iniciando suas considerações, a Igreja, presença religiosa dominante no mundo ocidental, moldou a figura feminina ao longo dos séculos criando um ideal a partir de duas figuras femininas centrais para o catolicismo, Eva e Maria. Antagonistas na tradição da Igreja, Eva, associada ao pecado, é aquilo o que a mulher é, e Maria representa o ideal a ser seguido.

Semelhante alusão é possível ser percebida no romance em questão. Luís da Silva mantém uma relação de analogia para com as demais personagens da narrativa. Em seguida, sua avó, sinha Germana, é o parâmetro de comparação, assemelhandose à figura de Maria, o exemplo a ser seguido; quanto as demais, Dona Mercedes, Antônia, inclusive Marina, seriam representações à imagem de Eva. Como bem ressalta Marcos Hidemi de Lima (2006): “O comportamento dessas mulheres é julgado e sentenciado pelo comportamento de sinhá Germana [...]” (2006: 101)

Determinada forma de julgamento advém principalmente de sua infância, retomada constantemente no romance pelo fluxo de consciência, aliado ao complexo uso da temporalidade. Deslocado no tempo e no espaço, Luís da Silva ainda se encontra fortemente ligado ao passado, remetendo-se em especial à figura de seu avô, Trajano, antes um importante fazendeiro da região. De acordo com Lima: "Com este olhar impregnado de valores já arruinados do passado o herói apreende a realidade. Por isso, por essa captação desfocada do passado que se entende a condição de deslocado de Luís da Silva”. (2006: 101)

Os padrões da época de infância do funcionário público servem como principal base de construção para o ideário deste personagem, em especial da imagem da 
mulher. Tedeschi (2014), referindo-se à construção da memória coletiva, que se dá a partir da relação entre individual e coletivo, comenta que:

[...] esses marcos da memória estão ligados à família, à religião, à classe social, e são portadores de representações da sociedade, de suas necessidades e valores. Incluem uma visão de mundo e ditam muitas vezes através de relações de poder os sentidos das identidades de gênero, da própria história, etc. (TEDESCHI, 2014: 40)

Como se pode perceber, a representação que se faz acerca dos demais elementos do romance estão sob a incidência da subjetividade de Luís da Silva. Logo, a influência de suas concepções recai sobre a sua vizinha Marina e o modo como a referida personagem configura-se na narrativa.

Um dos pontos que ligam as considerações do estudioso acerca da representação da mulher na história e o romance graciliânico é o fato de Marina ser uma jovem que gosta de se enfeitar. Ainda consoante o teórico, os discursos construídos ao longo da história sobre a mulher segundo uma cosmovisão aristotélica: “[...] empurrou as mulheres para o domínio do privado, do lar, e para os papéis sociais relacionados com ele [...]" (TEDESCHI, 2012: 67).

Nesse sentido, é possível depreender elementos de vaidade na personagem Marina a partir das observações do protagonista. Este, lendo um livro em seu quintal, percebeu uma movimentação estranha na propriedade ao lado e não reconhecendo os ágeis movimentos, diferentes da antiga vizinha que se movia "[...] tão devagar que parecia estar parada" (RAMOS, 1986:27), estava a indagar-se onde estava a senhora idosa, então, diz: "O vulto que se mexia não era a senhora idosa: era uma sujeitinha vermelhaça, de olhos azuis e cabelos tão amarelos que pareciam oxigenados." (RAMOS, 1986: 27). Além desta passagem, cabem aqui outras que ilustram a vaidade em Marina: “[...] cara pintada... Tinha as unhas pintadas.” (RAMOS, 1986: 27).

Atrelado a diversos momentos em que se apresentam traços de vaidade de Marina, manifesta-se também a irritação que tais características provocam em Luís da Silva. Ainda no contexto acima citado, o fato de a nova vizinha pintar as unhas provoca-lhe uma reação de adversidade, perceptível no fragmento a seguir:

E mergulhei na leitura, desatento, está claro, porque o livro não valia nada. Virava a página muitas vezes, e quando isto acontecia, olhava, fingindo desinteresse, a mulher dos cabelos de fogo. Tinha as unhas pintadas.

— Lambisgoia! (RAMOS, 1986: 27, grifo nosso)

Além deste, outros momentos podem ser utilizados para ressaltar como Silva se sentia perante os enfeites: "A mocinha, no lado de lá da cerca, não me dava atenção. Perua. Cabelos de milho, unhas pintadas, beiços vermelhos e o pernão aparecendo.” 
(RAMOS, 1986: 30, grifo nosso). Outros são os adjetivos cunhados na narrativa para referir-se a Marina: sujeitinha, burra, sirigaita.

Tal fato pode encontrar uma explicação à determinante exposta por Tedeschi (2012) de que a mulher, descendente da pecadora Eva, não deve adornar-se para não levar o homem ao pecado nem sair da esfera do privado.

As características e os comportamentos da primeira mulher são atribuídos a todo o gênero feminino, sendo Eva vista como o tipo representativo de todas as mulheres, a verdadeira essência feminina. Estas encarnam, portanto, a imagem de "filhas pecadoras de Eva”. [...] Traços arquétipos do feminino são encarnados por Eva (e por todas as mulheres) e enformam as atitudes morais face à sua mente e aparência. (TEDESCHI, 2012: 68)

Ainda refletindo sobre a posição que os elementos de adorno tomam na vida da mulher, embasando-se nas ideias de outros estudiosos, afirma: "Ela [Eva] é retratada como dissimulada por detrás de uma falsa decoração, usando a sua beleza e adornos como formas de arrastar os homens para a desgraça." (ALEXANDER apud TEDESCHI, 2014: 68). Para Tedeschi (2012: 68-69):

Esta visão está bem expressa no discurso católico que apela à renúncia do corpo e do prazer corporal por parte da mulher e à aparência casta. $[. . .]^{2}$ Caso contrário, não é apenas ela que peca

Sendo Angústia um romance em primeira pessoa, recai sobre a problemática da percepção, em que Marina, sentenciada pelo olhar de seu vizinho, é, em primeiro plano, representada como fútil, cujas tomadas de decisão têm como único intuito a aspiração social: sapatos, roupas e maquiagens são recursos além da parca condição de sua família: a mãe, dona de casa, e o pai um eletricista. Retratada como uma alpinista social, ela vive a procurar um homem com uma boa posição social que lhe permita ter acesso a seus desejos.

Mas esta interpretação, que tem por base as considerações de Luís da Silva, mostra-se precária, como explicado por Tedeschi (2012), uma vez que o ato de uma mulher se enfeitar e se adornar é motivo histórico de depreciação. Elenca-se a estas circunstâncias o fato de Luís da Silva não ser de confiança, pois não confia em si como ele mesmo relata: "Procuro recordar-me dos verões sertanejos, que duram anos. A lembrança chega misturada com episódios agarrados aqui e ali, em romances. Dificilmente poderia distinguir a realidade da ficção.” (RAMOS, 1986: 23, grifo nosso).

2 "Quero que as mulheres se apresentem em trajes honestos, decentes e modestos. Que os seus enfeites não consistam em tranças, em joias de ouro, nem em vestes luxuosas" - BÍBLIA SAGRADA. 1 Tim. 2: 9". (TEDESCHI, 2012: 68-69) 
Roberto Reis (apud Lima, 2006), centra-se em dois conceitos: núcleo e nebulosa. No primeiro, centra-se o dominador, o homem branco, o senhor patriarcal; e no segundo, o dominado, a mulher, o negro. Na condição de mulher, Marina pertence à nebulosa, e Luís da Silva deveria pertencer ao núcleo, por ser homem e descendente de uma família tradicional, apesar de em ruínas. Deveria, mas não pertence a este núcleo. Como advoga Lima, o narrador-personagem encontra-se: “[...] visivelmente instalado na nebulosa, juntamente com seus vizinhos e amigos, em certos momentos em que a lucidez lhe foge, julga pertencer ao núcleo." (LIMA, 2006: 74)

Com o desejo de pertencer ao núcleo, Marina, ciente de sua posição na sociedade, vê o casamento como único meio de escapar de sua situação de mulher submissa, afeiçoando-se a um homem que ela considere bem posicionado socialmente, que é o caso de Julião Tavares. Tais características ela julga ter encontrado em seu vizinho, um funcionário público que possui uma empregada doméstica, logo teria como tirá-la da condição da nebulosa.

Ao propor Marina em casamento, Luís da Silva considera que a tornaria sua posse, o que possivelmente contribuiria para que ele pudesse usufruir dela, alcançando a desejável relação sexual, já que os dois mantinham-se restritos apenas aos toques e beijos. Observemos o que comenta Tedeschi (2012: 100):

O que significa ser mulher (esposa) no espaço doméstico é fazer certos serviços para e sob o comando de um homem (marido). O contrato de casamento e a decorrente subordinação da esposa com um "tipo" de trabalhador não podem ser compreendidos na ausência do contrato sexual e da construção patriarcal dos "homens" e das "mulheres", nem fora das esferas "privadas" e "pública”.

Marina percebe que seu julgamento foi errôneo ao detectar a situação precária do noivo perante as compras do enxoval que queria. Os luxos desejados não puderam ser saciados e a moça começa então a expelir-se daquela relação.

A vizinha do protagonista considera ter encontrado em Julião Tavares a condição desejada. A filha de seu Ramalho enamora-se pelo sujeito rico, descrito pelo anti-herói Luís da Silva como: "[...] um sujeito gordo, vermelho, risonho, patriota, falador e escrevedor." (RAMOS, 1986: 35). A situação econômica e material de Tavares leva Marina a crer que o herdeiro da Tavares \& Cia é o candidato a tirá-la de sua condição. Todavia, o julgamento feito por ela é errôneo, pois Julião apenas a utiliza, expondo-a como objeto, como fruto de sua conquista, desfilando com ela pelos lugares.

Aos domingos iam ao cinema, juntos, de braço dado, bancando marido e mulher - ele com ar bicudo e saciado, ela bem-vestida como uma boneca e toda dengosa. Seda, veludo, peles caras, tanto 
ouro nas mãos e no pescoço que era uma vergonha. (RAMOS, 1986: 79)

Após a utilização do corpo de Marina, o antípoda segue para a próxima "vítima", deixando-a grávida e sozinha. Esta, impotente perante a sociedade, ciente de sua posição, entende o que espera uma mãe solteira àquela época - apesar de inexistirem no romance marcas temporais concretas, toma-se o tempo como na década de publicação, 1930. Como solução para sua situação, realizada um aborto.

Percebe-se, destarte, que em Angústia, o modo como a personagem feminina Marina é exposta no plano narrativo, já que, inicialmente, se percebe uma jovem fútil e supérflua. Mas a partir de uma análise na qual se pode averiguar o contexto histórico no qual ela estava inserida, entendem-se que os julgamentos transmitidos no romance não podem ser tomados como verdadeiros, pois Luís da Silva tem um olhar impregnado de concepções arcaicas cunhadas e transmitidas ao longo dos séculos acerca da figuração da mulher no espaço social.

Outrossim, o sistema patriarcal continua em plena vigência. A análise da situação de Marina demonstra o quão forte esta personagem é afetada por ele, tendo sua vida subordinada à vontade do varão como seu salvador pois está presa a uma atmosfera que inferioriza a mulher. Por isso a única solução encontrada por ela, desprovida de ação, marginalizada, consciente de sua inferioridade relativizada a seu sexo, é o homem.

\section{Considerações finais}

É bem verdade que sob o signo de regionalismo se produziu um conjunto de obras que deu feição à segunda geração do modernismo, na década de 1930. Mas a produção romanesca do período não se restringiu-se apenas a isso. Ao conjunto de obras legadas por Graciliano Ramos naquele decênio, encontra-se um profundo estudo dos problemas da alma (COUTINHO, 1997), salientando no romance graciliânico o caráter de universalidade.

Como visto no decorrer deste artigo, ainda que a principal temática dos quatro romances do Mestre Graça, publicados ao longo de 1930, ponha em primeiro plano o sujeito dentro de si mesmo, foi possível perceber uma crítica contundente à situação da mulher na sociedade daquela época, visto que nos romances de Graciliano a figura feminina encontra-se profundamente marcada por problemas de ordem cultural, bem como de uma sociedade herdeira do sistema patriarcal.

A partir das reflexões feitas a partir das considerações teóricas de Tedeschi (2012, 2014), foi possível notar como Marina, a personagem feminina em destaque no romance Angústia, foco deste trabalho, figura no plano narrativo, claramente assujeitada ao sistema que a imerge numa situação de imobilidade, ao se adotar o ponto de vista socioeconômico, que a impossibilita de outras oportunidades por si só, 
precisando ela recorrer ao homem, visto a adjetivação pejorativa que lhe é atribuída devido a suas atitudes. Além disso, a visão de um sujeito em profundo estado de perturbação contribui com a maneira pela qual o leitor percebe a personagem, pois é pela perspectiva de Luís da Silva que temos as informações sobre Marina.

\section{Referências}

BOSI, Alfredo. (1979). Pré-modernismo e modernismo. In: . História concisa da literatura brasileira. 6a ed. São Paulo: Cultrix.

. (1979). Tendências contemporâneas. In: . História concisa da literatura brasileira. 6a ed. São Paulo: Cultrix, 1979.

CANDIDO, Antônio. (1999) III - O sistema literário consolidado. In: Iniciação à literatura brasileira. $3^{\text {a }}$ ed. São Paulo: Humanitas/ FFLCH/USP.

CANDIDO, Antônio. (2006). Ficção e confissão. $3^{\underline{a}}$ ed. São Paulo: Ouro Sobre Azul.

CARPEAUX, Otto Maria. (1978). "Visão de Graciliano Ramos". In: BRAYNER, Sônya (Org.). Coleção fortuna crítica 2: Graciliano Ramos. 2ª ed. Rio de Janeiro: Civilização Brasileira. p. 25-33

COUTINHO, Afrânio. (1997) "O modernismo na ficção”. In: (dir.). COUTINHO, Eduardo de Faria (co-dir). Literatura no Brasil: era modernista. $4^{\text {a }}$ ed. rev. e atualiza. São Paulo: Global. p. 263-590

GIL, Fernando Cerisara. Angústia e o romance da urbanização. In.: O romance de urbanização. 1997, Tese (Doutorado em Letras) - COMPLEMENTAR Campinas, SP: Unicamp.

LAFETÁ, João Luiz. (2001). 1930: a crítica e o Modernismo. 34 $4^{\mathrm{a}}$ ed. São Paulo: Duas Cidades.

LIMA, Marcos Hidemi de. (2006) Os avessos da escrita. In: Mulheres de Graciliano: configurações femininas em S. Bernardo, Angústia e Vidas Secas. Londrina: UEL.

LIMA, R. S. (2019). Graciliano Ramos: uma voz isolada no romance de 1930. $2^{\underline{a}}$ Festa Literária de Palmeira dos Índios e a Semana Graciliano Ramos. Palmeira dos Índios, 2019 . 
MORAES, Dênis de. (2012). O velho Graça: uma biografia de Graciliano Ramos. 1.ed., rev. e ampl. São Paulo: Boitempo.

RAMOS, Graciliano. (2013). Angústia. 120a ed. Rio de Janeiro: Record.

TEDESCHI, Losandro Antonio. (2014). Alguns apontamentos sobre história oral, gênero e história das mulheres. Dourados, MS: UFGD.

(2012). As mulheres e a história: uma introdução teórico-metodológica. Dourados, MS: UFGD.

Recebido em 15/06/2020.

Aceito em 29/10/2020. 